Check for updates

Cite this: Sustainable Energy Fuels, 2020, 4, 302

Received 19th August 2019

Accepted 23rd October 2019

DOI: $10.1039 / c 9 s e 00679 f$

rsc.li/sustainable-energy

\section{Single step additive manufacturing (3D printing) of electrocatalytic anodes and cathodes for efficient water splitting $\dagger$}

\author{
Jack P. Hughes, ${ }^{\text {ab }}$ Pãmyla L. dos Santos, ${ }^{c}$ Michael P. Down, ${ }^{\text {ab }}$ \\ Christopher W. Foster, (iD) ab Juliano A. Bonacin, (D) ${ }^{c}$ Edmund M. Keefe, ${ }^{a}$ \\ Samuel J. Rowley-Neale (D)*ab and Craig E. Banks (D)*ab
}

\begin{abstract}
We enhance the current capability of additive manufacturing (AM)/(3D printing) to produce electronic devices by presenting a facile methodology for the production of electroconductive/electrocatalytic AM polylactic acid (PLA) filaments containing electrocatalytic materials; 2D-MoSe 2 (M), electro-conductive carbon (C) and 20\% Pt on carbon (Pt/C). The AM printed structures/electrodes (AMEs) produced using these filaments display bespoke electrochemical signals, in this case, efficient catalysis towards the major reactions that occur within a water electrolyser, namely the hydrogen evolution reaction (HER) on the cathode and the oxygen evolution reaction (OER) on the anode without the need for any postproduction treatments. Various percentage mass incorporations, of the additives, into the PLA filaments were explored, with a $25 \%$ mass incorporation representing an ideal compromise between electroactivity and printability. Utilizing the optimized $M_{10 \%}-C_{15 \%}-A M E$ and $P t / C_{25 \%}-A M E$ as the cathode and anode, respectively, whilst a commercially available alkaline battery applied a potential of $1.5 \mathrm{~V}$, water-splitting was achieved with obvious effervescence occurring at each electrode. This AM technique could mitigate the need for complex fabrication procedures, allowing researchers, industry and any interested individuals to rapidly go from 'desktop designs' to workable electrochemical prototype devices.
\end{abstract}

\section{Introduction}

Reducing the production costs of 'green hydrogen' could enable a plethora of hydrogen fuelled energy generation techniques to become cost competitive with their polluting fossil fuel based counterparts. ${ }^{1,2}$ A promising technique for the production of hydrogen is water splitting within an electrolyser, where the hydrogen evolution reaction (HER) $\left(2 \mathrm{H}^{+}+2 \mathrm{e}^{-} \rightarrow \mathrm{H}_{2}\right)$ occurs on the cathode. $^{3}$ Currently, there is a requirement within commercial electrolysers for relatively expensive platinum (Pt)

${ }^{a}$ Faculty of Science and Engineering, Manchester Metropolitan University, Chester Street, Manchester M1 5GD, UK. E-mail: S.Rowley-Neale@mmu.ac.uk; Fax: +44 (0) 1612476831; Tel: +44 (0)1612471196

${ }^{b}$ Manchester Fuel Cell Innovation Centre, Manchester Metropolitan University, Chester Street, Manchester M1 5GD, UK. E-mail: c.banks@mmu.ac.uk; Web: http://www. craigbanksresearch.com

'Institute of Chemistry, University of Campinas, P. O. Box 6154, 13083-970, Campinas, SP, Brazil

$\dagger$ Electronic supplementary information (ESI) available: Description of physicochemical characterization equipment. EDX elemental analysis of the AME electrodes surface. TEM images of the commercially sourced 2D-MoSe ${ }_{2}$, Super P and $20 \% \mathrm{Pt} / \mathrm{C}$. Characterization of the commercially sourced $2 \mathrm{D}-\mathrm{MoSe}_{2}$, Super $\mathrm{P}$ and $20 \% \mathrm{Pt} / \mathrm{C}$, including XRD, Raman and XPS. Thermogravimetric analysis of the AME variants. Raman analysis of the $\mathrm{Pt} / \mathrm{C}_{25 \%} \mathrm{AME}$ and $\mathrm{M}_{10 \%}-\mathrm{C}_{15 \%}$ AME. Hydrogen turnover frequency calculations (ToF). See DOI: 10.1039/c9se00679f and iridium (Ir) based catalysts to act as the cathodic and anodic materials, respectively. ${ }^{4,5}$ There are however, numerous studies within the literature demonstrating that novel $2 \mathrm{D}$ nanomaterials, in particular, the transition metal di-chalcogenides, ${ }^{6}$ such as $2 \mathrm{D}-\mathrm{MoS}_{2}$ and $2 \mathrm{D}-\mathrm{MoSe}_{2}$ can offer comparable activity, in regards to the HER onset potential and achievable current densities, whilst being cheaper and more earthly abundant..$^{7-9}$ One such study by Mao et al. ${ }^{10}$ demonstrated the deposition via DC-magnetron sputtering of $\mathrm{MoSe}_{2}$ films upon a graphitic substrate. The unmodified graphite electrode exhibited an overpotential and a Tafel value at a current density of $10 \mathrm{~mA} \mathrm{~cm}{ }^{-2}$ of $-495 \mathrm{mV}$ (vs. RHE) and $220.6 \mathrm{mV} \mathrm{dec}{ }^{-1}$, respectively, whereas the loading of $\mathrm{MoSe}_{2}$ upon the graphitic substrate resulted in a superior overpotential and Tafel value of $-125 \mathrm{mV}$ ( $v s$. RHE) and $52.1 \mathrm{mV} \mathrm{dec}^{-1}$, respectively. Theoretical studies suggest that it is the active edge planes, in particular the edge dangling electronegative Se atoms (with a binding energy towards $\mathrm{H}^{+}$of $\left.-0.05 \mathrm{eV}\right),{ }^{11}$ that exhibit the catalytic activity towards the HER, possessing exchange current densities close to that of the Pt-group metals, whilst the basal planes are relatively inert. ${ }^{12}$

Often studies that use $\mathrm{MoSe}_{2}$ based materials are disconnected between their research findings and the transfer to industry. This is due to their use of the drop-casting technique in order to modify a chosen electrode, typically glassy carbon 
(GC), and then explore the electrochemical behaviour of the given material. ${ }^{\mathbf{8} 13-15}$ Whilst drop-casting is an easy/convenient method to explore the electrochemical properties of a given material it has low levels of reproducibility/stability and cannot be reliably scaled for industrial use. A previous study by RowleyNeale et al. ${ }^{16}$ attempted to overcome this problem by incorporating $2 \mathrm{D}-\mathrm{MoSe}_{2}$ into the bulk of screen-printed electrodes. The resultant fabricated $\mathrm{MoSe}_{2}$-SPEs exhibited a HER onset and

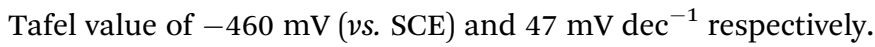
Through a technique (screen-printing) that has an application in industry, this study presented a partial bridge between research and industry however it is intrinsically limited to working in $2 \mathrm{D}^{17}$

The advent of additive manufacturing (AM)/3D printing technology could significantly decrease the time and cost associated with the design and fabrication of complex 3D structures. ${ }^{18}$ Hence, the emergence of this technology provides a convenient and low cost platform to produce prototypes/ components for a variety of applications. ${ }^{\mathbf{1 9 , 2 0}}$ One such application was a study by Chisholm et al. ${ }^{21}$ whom utilized AM in order to produce prototype PEM electrolyser flow plates from polypropylene. Whilst this study was imaginative in its use of $\mathrm{AM}$, the flow plates it produced were non-conductive before being electro-coated with silver and then sputter-coated with gold. The requirement for these additional post-AM coating steps significantly detracts from the low cost and ease of application benefits associated with the technique. Another study by Ambrosi et al. ${ }^{22}$ utilized a metal AM technique to fabricate electrolyser anodes and cathode geometries, these structures then underwent an electrodeposition step whereby Pt and $\mathrm{IrO}_{2}$ were electrodeposited on to the cathode and anode respectively. The electrodes exhibited considerable activity towards the HER and OER with onset potentials of $-0.1 \mathrm{~V}$ and $+1.6 \mathrm{~V}$, respectively.

While both the examples above are elegant in their use of $\mathrm{AM}$, they require post-AM modification steps to enable the printed structure to be used as an electrode. The inclusion of this additional production step increases the associated costs and fails to harness the full potential of AM, which ideally would enable the direct production of electrodes, from bespoke computer aided drawings, that can be used as-is and exhibit desirable electrochemical signal outputs with regards to their HER and OER activities. In order to capitalise upon the benefits of additive manufacturing it would be preferential to use an AM filament that was conductive/electrocatalytic in order to produce 3D architectures; namely, components for an electrolyser. A study by Foster et $a .^{23}$ has shown that it is possible to produce electrodes from electro-conductive filaments by creating AM electrodes (AMEs) using the commercially available graphene incorporated polylactic acid (PLA) filaments and explore their application within lithium-ion batteries and supercapacitors.

This paper, for the first time, outlines a facile technique for the fabrication of highly reproducible 2D-MoSe ${ }_{2}$-carbon/PLA and $\mathrm{Pt} / \mathrm{C}$ AM filaments. These filaments are subsequently AM (FFM) into operational electrolyser electrodes that exhibit low overpotentials and tailorable current densities without the requirement for any post-printing treatment. The potential of the displayed technology could mitigate complex fabrication techniques in the production of prototype electrolyser components, allowing researchers, industry and any interested individuals to rapidly go from desktop computer aided drawings/ designs (CAD) to workable prototypes, drastically reducing the cost and time associated with traditional prototyping.

\section{Results and discussion}

\subsection{Physicochemical characterization of the additives}

Physicochemical characterization was performed on the additives utilized in the AME production (namely $2 \mathrm{D}-\mathrm{MoSe}_{2}$, Super $\mathrm{P}$ and $20 \% \mathrm{Pt} / \mathrm{C}$ ) using Raman spectroscopy, TEM, XRD and XPS. TEM analysis was utilized in order to determine the average particle size of the additives. The 2D-MoSe 2 , Super P and Pt/C particles can be observed in ESI Fig. S1-S3† and were found to have average particle sizes of $c a .500,50$ and $100 \mathrm{~nm}$, respectively. The lattice fringe $d$-spacing, shown in ESI Fig. S1(A), $\dagger$ was found to be 0.3 and $0.6 \mathrm{~nm}$, corresponding to the (100) and (002) lattice planes of the bulk 2D-MoSe respectively. ${ }^{24}$ ESI Fig. S2(A) and S3(A) $\dagger$ present the crystalline fringe $d$-spacing of $0.3 \mathrm{~nm}$, corresponding to the (002) lattice plane in Super $\mathrm{P}^{25}$ and $d$-spacing of $0.2 \mathrm{~nm}$, corresponding to the (111) lattice plane in the $20 \% \mathrm{Pt} / \mathrm{C} .{ }^{26} \mathrm{XRD}$ analysis obtained for the $2 \mathrm{D}-\mathrm{MoSe}_{2}$ utilized herein is presented in ESI Fig. S4(A). $\dagger$ The characteristic diffraction peaks at $2 \theta=13.7^{\circ}, 37.8^{\circ}, 47.5^{\circ}$, $55.8^{\circ}$ and $56.7^{\circ}$ are assigned to the (002), (103), (105), (110) and (112) facets of the hexagonal face of $\mathrm{MoSe}_{2}$ (2H crystallinity) respectively. ${ }^{8,27}$ XRD analysis of Super P (see ESI Fig. S5(A) $\dagger$ ) exhibits two characteristic peaks at $2 \theta=25.0^{\circ}$ and $44.0^{\circ}$ corresponding to the diffraction planes (002) and (100). ${ }^{28,29}$ XRD analysis of the $20 \%$ PtC powder is presented in ESI Fig. S6(A), $\dagger$ where characteristic diffraction peaks at $2 \theta=25.6^{\circ}, 40.1^{\circ}, 46.5^{\circ}$, $59.9^{\circ} 67.8^{\circ}$ and $81.6^{\circ}$ are indexed to the (002), (111), (200), (004), (220) and (311) facets of the Pt on activated carbon support lattice. $^{30-32}$ Raman analysis was also implemented (see ESI Fig. $S 4(B) \dagger$ ), with a Raman spectra showing the $A_{1 g}$ and $E_{2 g}^{1}$ vibrational bands at $c a .238$ and $283 \mathrm{~cm}^{-1}$ respectively, which are two of the most prominent peaks associated with 2D-MoSe ${ }_{2}$, agreeing well with literature..$^{12,13,33}$ The $\mathrm{A}_{1 \mathrm{~g}}$ peak corresponds to the out-of-plane Mo-Se phonon mode whilst the $\mathrm{E}_{2 \mathrm{~g}}^{1}$ vibrational band is the in-plane mode. ${ }^{12,13,33}$ Raman analysis of Super $\mathrm{P}$ displayed characteristic vibrational bands D and $\mathrm{G}$ at $c a .1350$ and $1586 \mathrm{~cm}^{-1}$, as well as a broad band at $c a .2680 \mathrm{~cm}^{-1}$, corresponding to the $2 \mathrm{D}$ vibrational mode (ESI Fig. S5(B) $\dagger$ ). ${ }^{34}$ Raman analysis of the $20 \% \mathrm{Pt} / \mathrm{C}$ powder shown in ESI Fig. S6(B) $\dagger$ also presented the typical vibrational bands D and $\mathrm{G}$ observed in a carbon based material at ca. 1360 and $1589 \mathrm{~cm}^{-1}$, respectively. ${ }^{35,36}$ The $\mathrm{D}$ and $\mathrm{G}$ vibrational bands are both indicative of $\mathrm{sp}^{3}$ hybridisation in the activated carbon support of the $\mathrm{Pt} / \mathrm{C}$ or Super $\mathrm{P} .{ }^{37}$ The presence of a Pt signal is evident by the lack of a strong 2D band usually observed at $c a .2680 \mathrm{~cm}^{-1}$ as observed in the Super P spectra, moreover, the Pt/C spectrum displays a broad band between $2600-2950 \mathrm{~cm}^{-1}$, this suggests the presence of Pt nanoparticles has led to a significant reduction in the $2 \mathrm{D}$ band. ${ }^{38,39}$ XPS was utilized to investigate the 
binding energies within the 2D-MoSe ${ }_{2}$ nanoparticles, Super $\mathrm{P}$ and $20 \% \mathrm{Pt} / \mathrm{C}$ powders. Upon inspection of ESI Fig. S4(C) $\dagger$ binding energies are evident for both Mo $3 \mathrm{~d}^{5 / 2}$ and Mo $3 \mathrm{~d}^{3 / 2}$ at 229.0 and $232.3 \mathrm{eV}$ respectively, such analysis reveals a $\mathrm{Mo}^{4+}$ oxidation state. Note that the printing process is likely to create oxygenated species due to the high temperatures involved in the extrusion process, however this is a necessary step in the AMEs fabrication. Further study to investigate the creation of type of surface oxygenated species and their interaction with the HER and OER would be of interest. Also shown within ESI Fig. S4(D) $\dagger$ are binding energies for Se $3 \mathrm{~d}^{5 / 2}$ and Se $3 \mathrm{~d}^{3 / 2}$ positioned at 54.6 and $55.4 \mathrm{eV}$, indicating a $\mathrm{Se}^{2-}$ oxidation state. ${ }^{40}$ Analysis of Super P XPS spectra displayed in ESI Fig. S5(C) $\dagger$ shows the presence of a binding energy of $284.4 \mathrm{eV}$ corresponding to the $\mathrm{C}$ 1s orbital in Super P. XPS spectra for the $20 \%$ PtC powder, given in ESI Fig. S6(C)† exhibits the presence of a peak at $284.4 \mathrm{eV}$ relating to the $\mathrm{C} 1 \mathrm{~s}$ orbital. ESI Fig. S6(D) $\dagger$ displays the binding energies 71.1, 74.0 and $76.3 \mathrm{eV}$, corresponding to the $4 \mathrm{f}$ orbitals in $\mathrm{Pt}$, PtO and $\mathrm{PtO}_{2}$, respectively. Quantification by mass concentration of the $20 \%$ PtC powder revealed an elemental composition of $69.7 \%, 9.3 \%$ and $21.0 \%$ for $\mathrm{C}$, O and $\mathrm{Pt}$, respectively, hence confirming the correct percentage composition of the reagent used to synthesise the $25 \%$ PtC filament.

\subsection{Physicochemical characterization of the AMEs}

Upon production of the AME variants, TGA analysis was performed to ensure that they contained the selected percentage of additive content. ESI Fig. S7 $\uparrow$ depicts a phase transition of the $\mathrm{M}_{10 \%}-\mathrm{C}_{5 \%}, \mathrm{M}_{10 \%}-\mathrm{C}_{10 \%}, \mathrm{M}_{10 \%}-\mathrm{C}_{15 \%}$ and $\mathrm{Pt} / \mathrm{C}_{25 \%}$ PLA filaments over a temperature range of 25 to $850{ }^{\circ} \mathrm{C}$ in a nitrogen atmosphere. It is clear, that the PLA begins to thermally degrade at ca. $300{ }^{\circ} \mathrm{C}$ with the remaining percentage residue additive content being $10.3,15.4,26.2$ and $27.6 \%$ by $850{ }^{\circ} \mathrm{C}$, these values are within an acceptable range of those expected due to the fabrication process of $10,15,25$ and $25 \%$ for the $\mathrm{M}_{10 \%}-\mathrm{C}_{5 \%}$, $\mathrm{M}_{10 \%}-\mathrm{C}_{10 \%}, \mathrm{M}_{10 \%}-\mathrm{C}_{15 \%}$ and $\mathrm{Pt} / \mathrm{C}_{25 \%}$ PLA filaments, respectively. These findings attest to the reliability of the fabrication technique, as well as showing that the subsequent printing process of the modified will not affect the thermal properties or the percentage additive content of the bespoke PLA based filaments. It is important that the surface of the bespoke AMEs had exposed electrocatalytic materials $\left(\mathrm{MoSe}_{2}\right.$ and $\left.20 \% \mathrm{Pt} / \mathrm{C}\right)$ to ensure an optimal electrode-electrolyte interface, therefore SEM and EDX analysis was employed to determine if there was a uniform dispersion of the additives upon the polymer structures surface. Fig. 2(A1) and (B1) depict SEM images of the surface structure of a $\mathrm{M}_{10 \%}-\mathrm{C}_{15 \%}-\mathrm{AME}$ and a $\mathrm{Pt} / \mathrm{C}_{25 \%}-\mathrm{AME}$, it can be deduced that the electrodes had a diameter of $c a .3 .5 \mathrm{~mm}$ and a height of $1.5 \mathrm{~mm}$, which yielded a geometric surface area of $0.36 \mathrm{~cm}^{2}$ for the AMEs. This value was utilised as the electrode area for current density calculations. The $\mathrm{Pt} / \mathrm{C}_{25 \%}-\mathrm{AME}$ had a significantly rougher surface than that of the $\mathrm{M}_{10 \%}-\mathrm{C}_{15 \%}$ AME (note, the electrochemical analysis demonstrates that the mass transport occurring at either electrodes surface was due to diffusional processes and were not resulting from a thin layer/ film effect). Fig. 2(A2) is an SEM image of a section of a $\mathrm{M}_{10 \%}-\mathrm{C}_{15 \%}$-AME, Fig. 2(A3)-(A6) show EDX mapping of the molybdenum, selenium, oxygen and carbon content of this section. It is clear from this figure and ESI Table S1† that there is a homogenous distribution of carbon (62.6\%) and oxygen $(29.4 \%)$ that can be accounted for by the PLA and added Super $\mathrm{P}$. There is also a uniform surface coverage of Mo (2.8\%) and Se $(5.1 \%)$ as a result of the added $\mathrm{MoSe}_{2}$ nanoflakes. Note, that the Mo and Se is in a ca. 1:2 ratio expected from $\mathrm{MoSe}_{2}$. In the case of the Pt/C $\mathrm{C}_{25 \%}$-AME (see ESI Table S1, $\dagger$ Fig. 2(B4) and (B5)) there is a uniform coverage of carbon (56.8\%) and oxygen (35.2\%), which is a result of the PLA filament. Fig. 2(B3) also displays the expected uniform presence of $\mathrm{Pt}(8.1 \%)$ upon the electrode surface as a result of the incorporation of $\mathrm{Pt} / \mathrm{C}$ at a mass percentage of the total mix of $25 \%$. The analysis above shows that the fabricated AME contains the desired masses of additives and that they are uniformly distributed upon the electrode surface where they can interact with the electrolyte. Raman analysis was performed on the AMEs and shown within ESI Fig. S8. $\uparrow$ The Raman spectrum of PLA exhibited characteristic

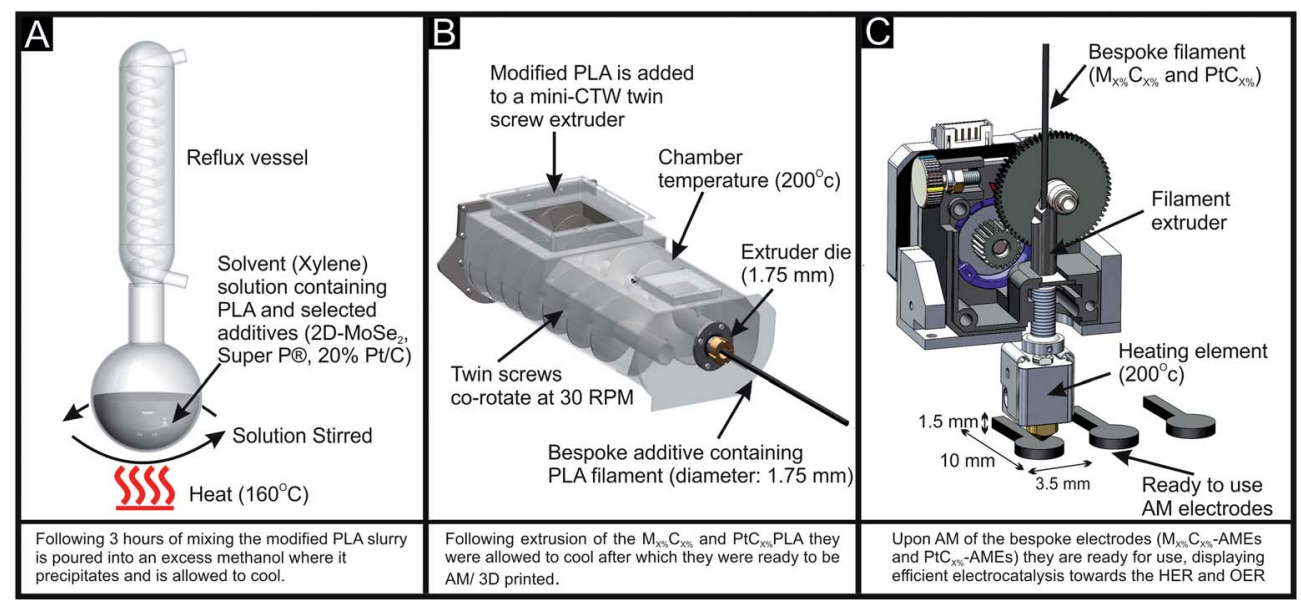

Fig. 1 Schematic showing the incorporation of the additive materials within the PLA (A), the extrusion of modified PLA into a filament that can be additively manufactured (B) and the additive manufacturing of ready to use electrodes with bespoke electrochemical activity (C). 


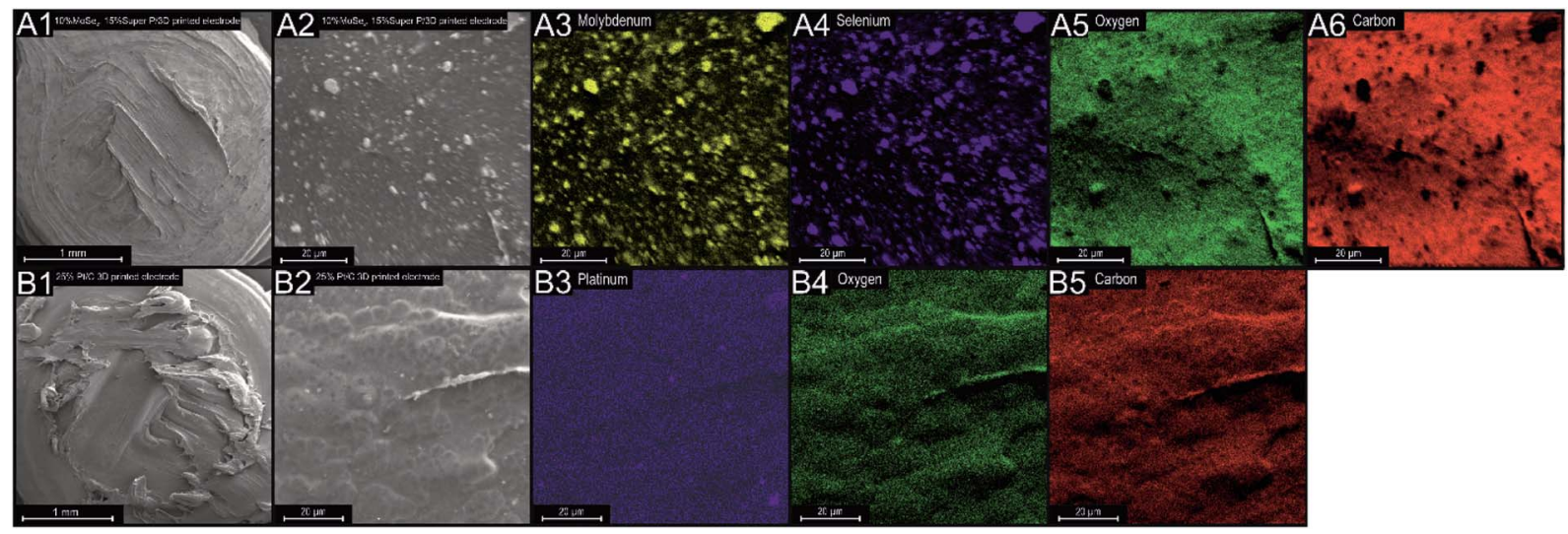

Fig. 2 SEM and EDX elemental mapping analysis of the $M_{10 \%}-C_{15 \%}-A M E(A)$ and $P t / C_{25 \%}-A M E(B)$.

bands at $873,1455,1770$ and $2946 \mathrm{~cm}^{-1}$. The prominent band at $2946 \mathrm{~cm}^{-1}$ is assigned to the $\mathrm{CH}_{3}$ symmetric stretch. The peaks at 873 and $1455 \mathrm{~cm}^{-1}$ are the $\nu \mathrm{C}-\mathrm{COO}$ and $\delta \mathrm{CH}_{3}$ asymmetric modes, respectively while the band located at $1771 \mathrm{~cm}^{-1}$ is assigned to $\mathrm{C}=\mathrm{O}$ stretching. ${ }^{\mathbf{4 1}}$

\subsection{Electrochemical performance of the AMEs towards the HER and OER}

The AMEs were characterised, with regards to their HER and OER activity. This was carried out using a typical three-electrode system, where a given AME acted as the working electrode, with a large area nickel mesh and Reversible Hydrogen Electrode (RHE) acted as the counter and reference electrodes, respectively (see Fig. 3(A)). Note, all the experiments were carried out in deoxygenated (nitrogen bubbled) $0.5 \mathrm{M} \mathrm{H}_{2} \mathrm{SO}_{4}$ or $0.1 \mathrm{M} \mathrm{KOH}$. Fig. 3(B) shows the linear sweep voltammetry (LSV) obtained for the $\mathrm{M}_{10 \%}-\mathrm{C}_{5 \%}, \mathrm{M}_{10 \%}-\mathrm{C}_{10 \%}, \mathrm{M}_{10 \%}-\mathrm{C}_{15 \%}, \mathrm{C}_{15 \%}, \mathrm{Pt} / \mathrm{C}_{25 \%}$ AMEs and a polycrystalline $\mathrm{Pt}$ electrode. The $\mathrm{Pt}$ electrode shows optimal HER activity with a HER onset of $\left(-0.01 \mathrm{~V}\right.$ (vs. RHE) ${ }^{42}$ It is important to note, efforts to produce a pure Pt powder based filament were not successful. This was likely a result of the relatively high density of $\mathrm{Pt}$ powder $\left(21.45 \mathrm{~g} \mathrm{~cm}^{-3}\right),{ }^{43}$ in comparison to that of PLA $\left(1.25 \mathrm{~g} \mathrm{~cm}^{-3}\right)$. This resulted in a poor dispersion of Pt powder within the PLA when it was incorporated on a weight\% basis, or the degradation of the filaments structural integrity due to too small an amount of PLA being present within the filament. Therefore, a filament was produced using a commercially available $20 \% \mathrm{Pt}$ on Vulkan carbon (Pt/C) that had a comparable density to that of PLA. A 25\% loading of $\mathrm{Pt} / \mathrm{C}$ yielded an AME $\left(\mathrm{Pt} / \mathrm{C}_{25 \%}\right.$-AME) that had the least electronegative HER onset potential of all the AMEs produced at $-0.09 \mathrm{~V}$ (vs. RHE). The $\mathrm{C}_{15 \%}$-AME displayed the most electronegative HER onset potential at $-0.68 \mathrm{~V}$ ( $v s$. RHE), this can be accounted for by the presence of only electroconductive carbon within the PLA AME and no material that displays efficient HER catalysis. Incorporating $\mathrm{MoSe}_{2}$ into the conductive carbon containing AMEs resulted in a reduction in the electronegativity of the HER onset potentials, with the $\mathrm{M}_{10 \%}-\mathrm{C}_{5 \%}, \mathrm{M}_{10 \%}-\mathrm{C}_{10 \%}$ and $\mathrm{M}_{10 \%}-\mathrm{C}_{15 \%}$ AMEs displaying HER onsets of $-0.37,-0.36$ and $-0.30 \mathrm{~V}(v s$. RHE), respectively. It can be observed that the larger the percentage incorporation of conductive carbon within the AMEs, the greater the achievable current densities, with the $\mathrm{M}_{10 \%}-\mathrm{C}_{5 \%}, \mathrm{M}_{10 \%}-\mathrm{C}_{10 \%}$ and $\mathrm{M}_{10 \%}-\mathrm{C}_{15 \%}$ AMEs achieving current densities of $-1.31,-2.72$ and $-12.58 \mathrm{~mA} \mathrm{~cm}^{-2}$ by $1.0 \mathrm{~V}$ ( $v s$. RHE), respectively. The $\mathrm{M}_{10 \%}-\mathrm{C}_{15 \%}$-AME displayed the optimal HER activity of the non-Pt containing electrodes, this is likely as a result of the $\mathrm{MoSe}_{2}$ offering highly active HER catalysis, due to the exposed Se atoms at its active edge sites, whilst the 15\% incorporation of conductive carbon offered the greatest number of electrical pathways through the AME. The HER activity of the $\mathrm{M}_{10 \%}-\mathrm{C}_{15 \%}$-AME was explored within a solution of $0.1 \mathrm{M} \mathrm{KOH}$ with the obtained LSV being shown in Fig. 3(B). The observed HER onset potential was $-0.8 \mathrm{~V}$ (vs. RHE), which was $0.56 \mathrm{~V}$ more electronegative than the HER onset observed within a $0.5 \mathrm{M} \mathrm{H}_{2} \mathrm{SO}_{4}$ solution. This shows that the $\mathrm{M}_{10 \%}-\mathrm{C}_{15 \%} \mathrm{AME}$ offers significantly greater HER catalysis in an acidic over an alkaline solution. Note, that an AME containing a ratio of $10 \%$ $\mathrm{MoSe}_{2}$ to $90 \%$ PLA was produced and electrochemically evaluated, however it was found to display negligible electrochemical activity and therefore the data is not presented within this manuscript. Note that by performing cyclic voltammetry and plotting peak height versus square root scan rate revealed a linear response, which suggests the mass transport recorded from the AMEs was found to be solely diffusional in nature and that there was no trapped electrolyte/thin film effect occurring.

Next, it was important to assess the HER reaction mechanism occurring at each of the fabricated AMEs, this was done using Tafel analysis as is common within the literature. ${ }^{\mathbf{4 - 4 6}}$ The activity of a HER catalyst is related to the kinetic barrier of the rate-determining hydrogen evolution pathway with three separate rate limiting steps being identified. Those being the initial adsorption of a hydrogen atom onto the electrode by the Volmer step (characterised by a Tafel slope of $120 \mathrm{mV} \mathrm{dec}^{-1}$ ), and the Heyrosky (40 $\mathrm{mV} \mathrm{dec}^{-1}$ ) and Tafel $\left(30 \mathrm{mV} \mathrm{dec}^{-1}\right) \mathrm{H}_{2}(\mathrm{~g})$ discharge steps. Tafel analysis of the faradaic regions in the LSV's represented in Fig. 3(B) yielded the Tafel slopes shown in Fig. 3(C). The Pt electrode and $\mathrm{Pt} / \mathrm{C}_{25 \%}$ AME exhibited Tafel slope values of 21 and $43 \mathrm{mV} \mathrm{dec}^{-1}$, respectively whilst the $\mathrm{M}_{10 \%}-\mathrm{C}_{5 \%}, \mathrm{M}_{10 \%}{ }^{-}$ $\mathrm{C}_{10 \%}$ and $\mathrm{M}_{10 \%}-\mathrm{C}_{15 \%}$ AMEs exhibited Tafel slopes of 153, 123

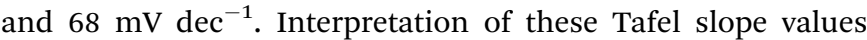




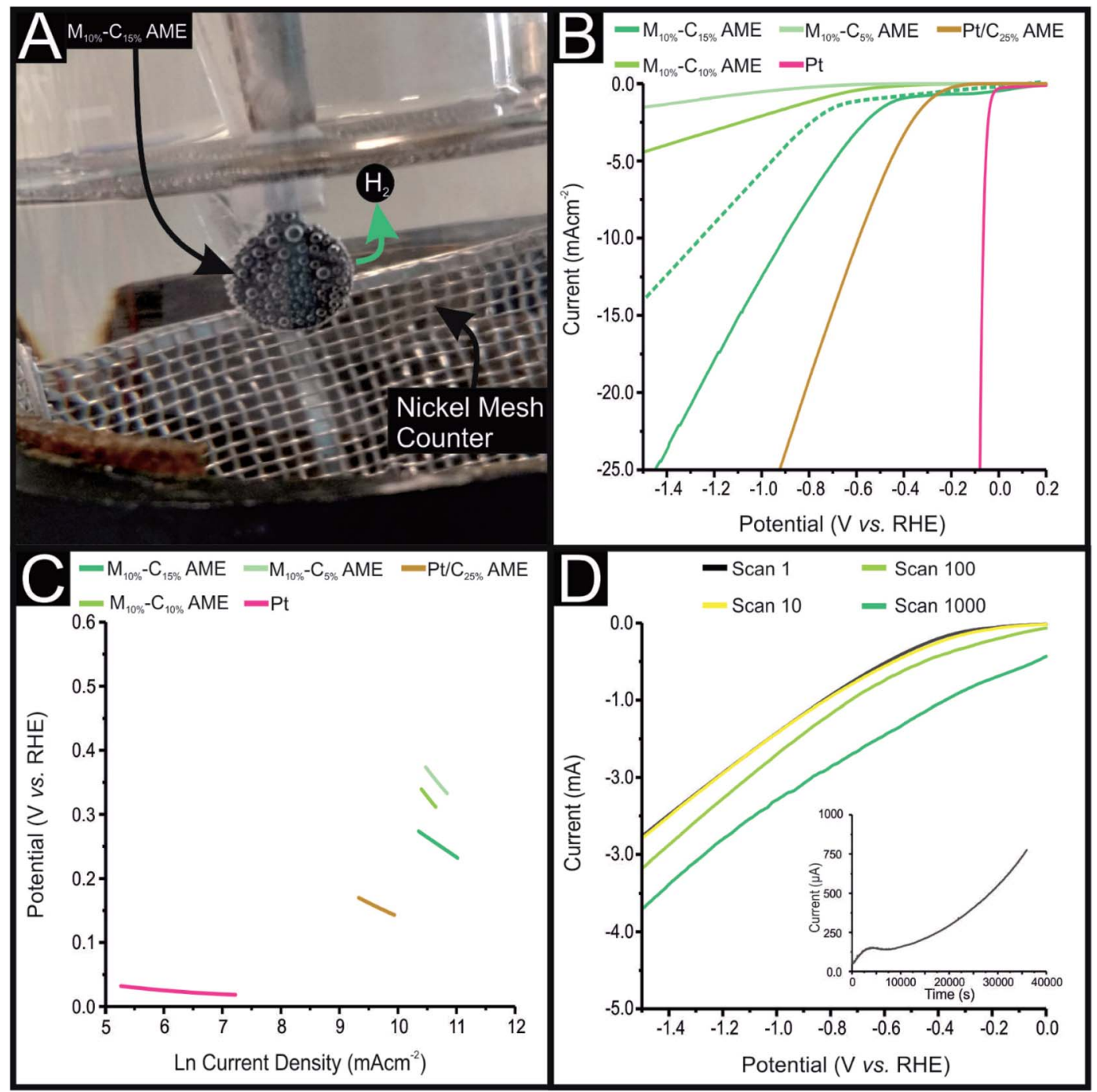

Fig. 3 (A) Image of the $M_{10 \%}-C_{15 \%}$ AME as the working electrode (cathode), which is clearly bubbling in a typical three cell system, with a nickel mesh counter electrode and RHE reference electrode. (B) Linear sweep voltammetry of unmodified and various modified electrodes showing HER activity of a polycrystalline platinum electrode, $M_{10 \%}-C_{5 \%}, M_{10}-C_{10 \%}, M_{10 \%}-C_{15 \%}, C_{15 \%}$ and Pt/ $C_{25 \%}$ AMEs, solution composition: 0.5 M $\mathrm{H}_{2} \mathrm{SO}_{4}$; scan rate: $10 \mathrm{mV} \mathrm{s}^{-1}$. Note, the dark green dotted line displays the $\mathrm{LSV}$ obtained for $\mathrm{M}_{10 \%}-\mathrm{C}_{15 \%}$, solution composition: $0.1 \mathrm{M} \mathrm{KOH}$; scan rate: $10 \mathrm{mV} \mathrm{s}^{-1}$ (C) Tafel slopes corresponding to the faradaic regions of the LSVs shown in (B). (D) Cyclic stability examination of a $M_{10 \%}-C_{15 \%}$ AME via LSV (scan rate: $100 \mathrm{mV} \mathrm{s}^{-1}$ ) was performed between the potential range of 0 to $-1.5 \mathrm{~V}$ (vs. RHE), repeated for 1000 cycles (inset: chronoamperometry for 36000 seconds at $-0.60 \mathrm{~V}$ (vs. RHE).

allowed for the rate-limiting step to be determined in each case. As predicted by the literature the Pt electrode allowed the reaction to occur via the desirable Volmer-Tafel mechanism ${ }^{5,9}$ whilst the $\mathrm{Pt} / \mathrm{C}_{25 \%}$-AME allowed the HER to occur via the Volmer-Heyrosky mechanism. The rate-limiting step for the $\mathrm{M}_{10 \%}-\mathrm{C}_{5 \%}$ and $\mathrm{M}_{10 \%}-\mathrm{C}_{10 \%}$ AMEs was the initial adsorption step showing that these electrodes exhibit poor HER catalysis. The $\mathrm{M}_{10 \%}-\mathrm{C}_{15 \%}$ AME Tafel slope suggests that the reaction mechanism likely follows the Volmer-Heyrosky mechanism and therefore displays good HER catalysis. The repeatability of each electrode towards the HER and OER was assessed using the $\mathrm{M}_{10 \%}-\mathrm{C}_{10 \%}$ and $\mathrm{Pt} / \mathrm{C}_{25 \%}$-AME's as representative examples, with $\%$ RSD values of 4.89 and $2.26 \%$, respectively. The intrinsic electrocatalysis exhibited by the $\mathrm{M}_{10 \%}-\mathrm{C}_{10 \%}$ and $\mathrm{Pt} / \mathrm{C}_{25 \%}$-AME's was calculated by a $\mathrm{H}_{2}$ Turn over Frequency (ToF) calculation. These ToF calculations are presented in the ESI. $\dagger$ The $\mathrm{M}_{10 \%}-$ $\mathrm{C}_{15 \%}$ and $\mathrm{Pt} / \mathrm{C}_{25 \%}$-AME's yielded ToF values of $0.0015 \mathrm{~s}^{-1}$ and $0.0018 \mathrm{~s}^{-1}$, respectively. These values imply that the AMEs display efficient electrocatlysis towards the HER with the Pt, as expected, displaying the greater per active site catalysis. Note that it was important to determine the electrochemical working area of the AMEs in order to accurately determine the TOF, the $\mathrm{M}_{10 \%}-\mathrm{C}_{15 \%}$ and $\mathrm{Pt} / \mathrm{C}_{25 \%}$-AME's were found to have electrochemical working areas of 0.46 and $0.35 \mathrm{~cm}^{2}$, respectively. These electrochemical area values were determined using the near ideal redox probe $\left[\mathrm{Ru}\left(\mathrm{NH}_{3}\right)_{6}\right]^{3+/ 2+}$ and the methodology described by Garcia-Miranda et al. ${ }^{47}$ It is clear from the deduced electrochemical areas of the AMEs that the majority of the AMEs 
surface $\left(0.36 \mathrm{~cm}^{2}\right)$ is electrochemically active. This implies that the AME production produces a homogeneous coverage of the electroconductive additives across the surface of the AMEs. This is due to the random distribution of the catalyst within the PLA filament. To ensure that these area values were accurate the real surface area of the $\mathrm{Pt} / \mathrm{C}_{25 \%}$-AME was determined by hydrogen adsorption using the $\mathrm{CV}$ technique described by Rodríguez et $a l .{ }^{48}$ The obtained CV can be observed in ESI Fig. S9† with the determined area of the $\mathrm{Pt} / \mathrm{C}_{25 \%}$-AME of $0.36 \mathrm{~cm}^{2}$ matching closely to the actual and electrochemical area. This supports the utilisation of the electrochemical area calculations used within the TOF values.

It was important to assess the stability of the fabricated AMEs electrochemically, so a $\mathrm{M}_{10 \%}-\mathrm{C}_{15 \%}$ AME was utilized as a representative example for the AMEs and subjected to 1000 repeat cyclic voltammograms (CVs) and chronoamperometry for 36000 seconds, the results of which are displayed in Fig. 3(D). $M_{10 \%}-C_{15 \%}$ AME signal output remained stable from the $1^{\text {st }}$ to the $10^{\text {th }}$ scan with a HER onset potential of $c a .-0.30 \mathrm{~V}$ (vs. RHE). There was a significant increase in the achievable current density from the $10^{\text {th }}$ to $100^{\text {th }}$ and $100^{\text {th }}$ to the $1000^{\text {th }}$ CVs, whist the current deviated increasingly away from the baseline. The HER onset potential was difficult to accurately determine for the $100^{\text {th }}$ and the $1000^{\text {th }} \mathrm{CV}$. The increase in background current observable in the $100^{\text {th }}$ and $1000^{\text {th }} \mathrm{CV}$ scan is likely a result of the PLA degrading within the $0.5 \mathrm{M} \mathrm{H}_{2} \mathrm{SO}_{4}$ over the course of the scan and revealing more electrocatalytic $\mathrm{MoSe}_{2}$ active edge sites and electro-conductive carbon. The inset in Fig. 3(D) shows the signal output (current) exhibited by a $\mathrm{M}_{10 \%}-\mathrm{C}_{15 \%}$ AME when chronoamperometry was performed at $-0.60 \mathrm{~V}$ ( $v s$. RHE) for 36000 seconds. In a similar trend to the 1000 repeat $\mathrm{CV}$ scans, there was a clear increase in achievable current from ca. $160 \mu \mathrm{A}$ at $8000 \mathrm{~s}$ to $c a .810 \mu \mathrm{A}$ at $36000 \mathrm{~s}$, representing a $506 \%$ increase, likely a result of the increased exposed electroactive edge sites of the additive materials due to the degradation of the PLA.
In order to utilize the AMEs in unison as the anode and cathode within a water-splitting device, it was necessary to explore the optimized $\mathrm{M}_{10 \%}-\mathrm{C}_{15 \%}$ and $\mathrm{Pt} / \mathrm{C}_{25 \%}$ AMEs towards the OER. Fig. 4(A) shows the obtained LSVs for a pure iridium (Ir) electrode, $\mathrm{M}_{10 \%}-\mathrm{C}_{15 \%}$ and $\mathrm{Pt} / \mathrm{C}_{25 \%}$ AMEs in $0.1 \mathrm{M} \mathrm{KOH}$. The iridium (Ir) electrode has the least electropositive OER potential at $+0.48 \mathrm{~V}$ ( $v s$. RHE) with the $\mathrm{M}_{10 \%}-\mathrm{C}_{15 \%}$ and $\mathrm{Pt} / \mathrm{C}_{25 \%}$ displaying OER onset potentials of $+0.9 \mathrm{~V}$ and $+0.5 \mathrm{~V}$ ( $v s$. RHE), respectively. The OER activity of the optimized $\mathrm{Pt} / \mathrm{C}_{25 \%} \mathrm{AME}$ was explored within a $0.5 \mathrm{M} \mathrm{H}_{2} \mathrm{SO}_{4}$ solution, with the obtained LSV displayed within Fig. 4(A). The observed OER onset potential was $+0.69 \mathrm{~V}$ (vs. RHE), which was $0.19 \mathrm{~V}$ more electropositive than the obtained OER onset potential within a $0.1 \mathrm{M} \mathrm{KOH}$ solution. It is clear that the $\mathrm{Pt} / \mathrm{C}_{25 \%}$ AME displays preferential OER activity within an alkaline rather than an acidic solution. Tafel analysis of the faradaic regions of the LSVs shown in Fig. 4(A) was performed with the Tafel slopes corresponding to values of 39, 137 and $247 \mathrm{mV} \mathrm{dec}^{-1}$ (see Fig. 4(B)). This clearly suggests that the $\mathrm{Ir}$ displays characteristic excellent OER activity whilst the $\mathrm{Pt} / \mathrm{C}_{25 \%}$ AME and $\mathrm{M}_{10 \%}-\mathrm{C}_{15 \%}$-AMEs display moderate and poor electrocatalytic activity towards the OER, respectively. As described above for the Pt powder, it was not feasible to produce an Ir powder containing AME due to its high density $\left(22.65 \mathrm{~g} \mathrm{~cm}^{-3}\right){ }^{49}$ therefore a $\mathrm{Pt} / \mathrm{C}_{25 \%} \mathrm{AME}$ was chosen to act as the anodic material, to catalyse the OER, within the water splitting device.

Once the catalytic performance of the AMEs had been physiochemically and electrochemically characterized and shown to be electrocatalytically active towards the HER and OER, we have for the first time, using any previous manufacturing technique, the opportunity to design and directly fabricate electrolyser anodes and cathodes in any geometry/structure we desired. Fig. 5(A) demonstrates a proofof-concept for the above, we designed hexagonal lattice structures using a CAD software and then printed the design using the $\mathrm{M}_{10 \%}-\mathrm{C}_{15 \%}$ and $\mathrm{Pt} / \mathrm{C}_{25 \%}$ filaments. The fabricated large area $\mathrm{M}_{10 \%}-\mathrm{C}_{15 \%}$ and $\mathrm{Pt} / \mathrm{C}_{25 \%}$ AMEs were utilized as the cathode and

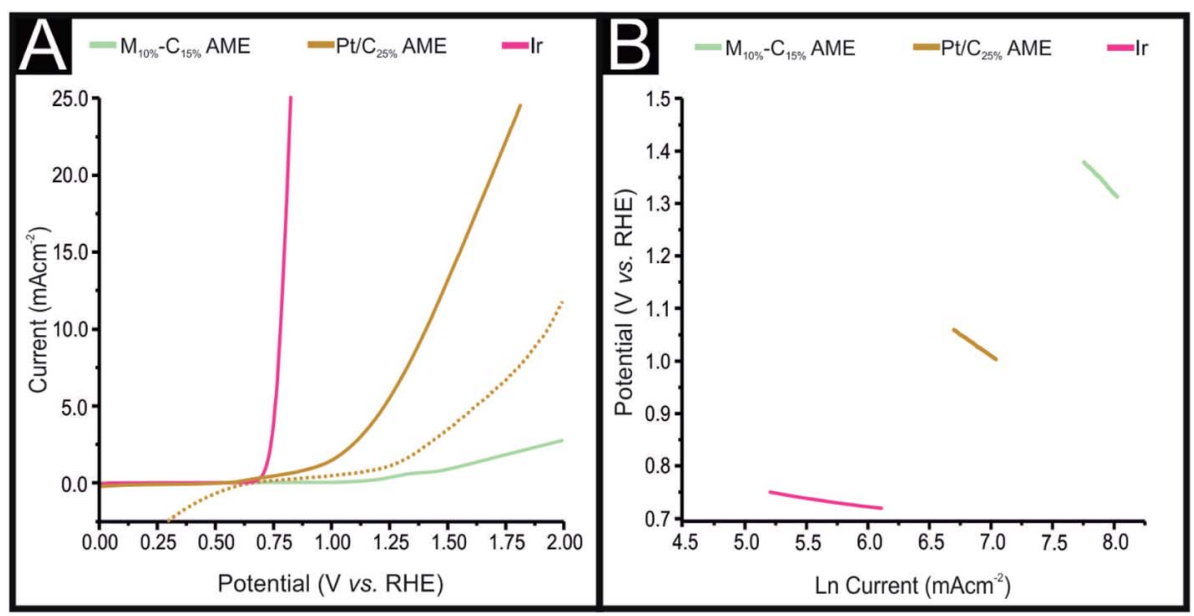

Fig. 4 (A) Linear sweep voltammetry showing the OER activity of a polycrystalline platinum electrode $M_{10 \%} C_{15 \%}, P t / C_{25 \%} A M E s$ and a polycrystalline Ir electrode, solution composition: $0.1 \mathrm{M} \mathrm{KOH}$; scan rate: $10 \mathrm{mV} \mathrm{s}^{-1}$. Note, the dark yellow dotted line displays the LSV obtained for Pt/ $\mathrm{C}_{25 \%} \mathrm{AME}$, solution composition: $0.5 \mathrm{M} \mathrm{H}_{2} \mathrm{SO}_{4}$; scan rate: $10 \mathrm{mV} \mathrm{s}^{-1}$ (B) Tafel slopes corresponding to the faradaic regions of the LSVs shown in (A). 


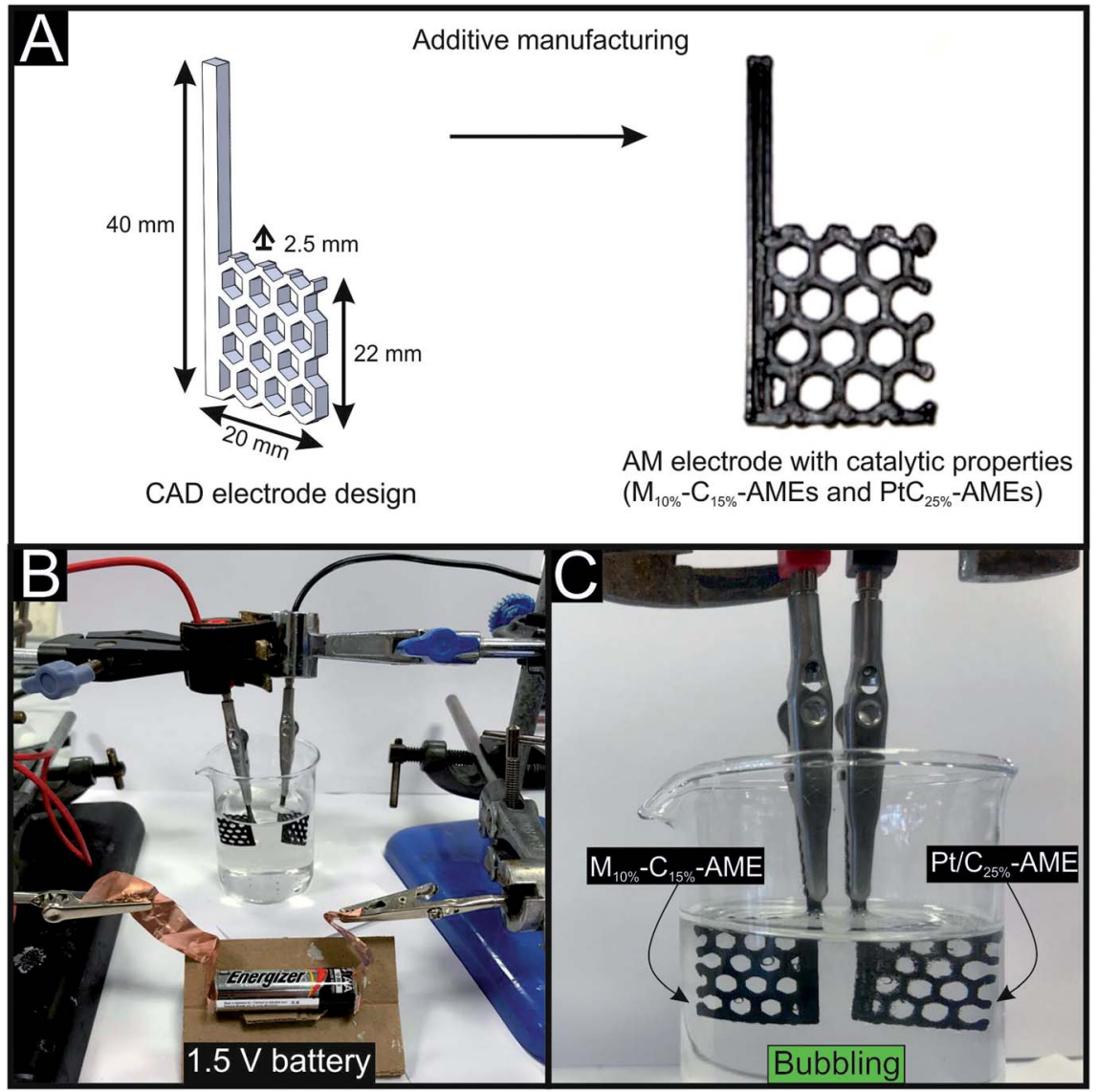

Fig. 5 (A) CAD design for a high surface area electrode and an electrode that has been additively manufactured utilizing this design using a byspoke electrocatalytic filament. ( $B$ and $C$ ) Image of water splitting enabled utilizing a $M_{10 \%} C_{15 \%}$-AME and a Pt/C $25 \%$-AME as the cathode and anode, respectively. Solution composition: $0.5 \mathrm{M} \mathrm{H}_{2} \mathrm{SO}_{4}$. Cell voltage applied using a commercially available alkaline zinc-manganese dioxide $1.5 \mathrm{~V}$ battery.

anodes within a water splitting device (see Fig. 5(B)) where the solution composition was $0.5 \mathrm{M} \mathrm{H}_{2} \mathrm{SO}_{4}$ and the cell voltage was applied using a commercially available alkaline zinc-manganese dioxide $1.5 \mathrm{~V}$ battery. As can be seen in Fig. 5(C) there was a significant amount of bubbling observed as hydrogen was formed at the cathode and oxygen was formed at the anode. A liquid impermeable case was designed and AM printed using a Projet MJP 2500 plus@ 3D printer with Visijet PXL@ polymer resin in order to house the electrolyte and the novel AMEs. This novel fabrication route has the clear potential to produce completely bespoke electrolysers using a single manufacturing stage as a multi-nozzle AM printer could be used to print the case, anode and cathode in situ.

\section{Conclusions}

The concept of AM printable filaments that have entirely tuneable electrochemical properties have been reported. To this end, we have presented a facile technique of incorporating $\mathrm{MoSe}_{2} / \mathrm{C}$ and Pt/C into PLA to obtain filaments that are utilized in the production of additive manufactured/3D printed electrodes (AMEs), of which their electrochemical properties towards hydrogen and oxygen evolution are greatly improved comparable to carbon-based counterparts. Using a commercially available alkaline zinc-manganese dioxide battery to apply a potential of $1.5 \mathrm{~V}$, we were able to observe hydrogen and oxygen gas effervescence at the cathode and anode, respectively and therefore, with the use of polymer/FFM additive manufacturing, produce a proof-of-concept water electrolyser unit. With the bespoke filaments that we have produced, it is now possible to attain AM electrochemical devices that are highly active with respect to water-splitting. The ability to produce a water-splitting device solely using a 3D printer and these bespoke filaments described herein has the potential to allow communities which have access to water and require fuel, in this case hydrogen for burning or use within a fuel cell, to simply and rapidly produce hydrogen. Furthermore, the process has demonstrated the potential to reduce the quantities of expensive and dwindling electrocatalytic materials, by developing a additive manufacturing feedstock with a relatively low filler density. This provides a platform to redesign the electrode structures further to maximise the areal efficiency maximising the benefits of additive manufacturing as a platform. This work has the potential to expose a plethora of electrochemical applications using bespoke AM filaments which can be electrochemically tuneable by varying their composition towards the desired application. 


\section{Experimental section}

\subsection{Chemicals}

All chemicals used were of analytical grade and were used as received from Sigma-Aldrich without any further purification. This includes the $\mathrm{MoSe}_{2}$, which has a reported purity of $99.9 \%$ on a trace metal basis, ${ }^{50}$ and the $20 \% \mathrm{Pt} / \mathrm{C}^{51}$ The electroconductive carbon black utilized "Super $\mathrm{P}{ }^{\circledR}$ " was purchased separately from Alfa Aesar. ${ }^{52}$ All solutions were prepared with deionised water of resistivity not less than $18.2 \mathrm{M} \Omega \mathrm{cm}^{-1}$ and were vigorously degassed prior to electrochemical measurements with high purity, oxygen free nitrogen. All measurements were performed in $0.5 \mathrm{M} \mathrm{H}_{2} \mathrm{SO}_{4}$ or $0.1 \mathrm{M} \mathrm{KOH}$. Note the sulfuric acid solution and potassium hydroxide powder utilized was of the highest possible grade available from Sigma-Aldrich (99.999\%). Note, where the HER and OER onset potentials are denoted within the manuscript, this is defined as the potential at which the current initially deviates from the background current by a value of $25 \mu \mathrm{A} \mathrm{cm}{ }^{-2}$, thus signifying the commencement of the faradaic current associated with the HER and OER redox reactions.

\subsection{Electrochemical measurements}

Electrochemical measurements were performed using an Ivium Compactstat $^{\mathrm{TM}}$ (Netherlands) potentiostat. Measurements were carried out using a typical three-electrode system with a nickel mesh counter electrode and Reversible Hydrogen Electrode (RHE) reference. The working electrodes utilized were AMEs that served as the cathode and/or anode dependent upon the experiment.

\subsection{Physicochemical characterization equipment}

The specifics of the Raman spectroscopy, Scanning Electron Microscope (SEM) with energy-dispersive X-ray microanalysis (EDX), Transmission Electron Microscopy (TEM), X-ray diffraction (XRD) and X-ray Photoelectron Spectroscopy (XPS) equipment utilized in order to characterise are all fully described within the ESI. $\dagger$

\subsection{Additive manufactured electrode fabrication}

The 2D-MoSe 2 /Super-P (electro-conductive carbon)/PLA filament was fabricated in-house via the process summarized within Fig. 1. Initially it was important to ascertain the optimal mass of $2 \mathrm{D}-\mathrm{MoSe}_{2}$ incorporation into an AME. The 2D-MoSe was incorporated into the bulk of the PLA on the basis of the weight percent of $M_{\mathrm{P}}$ and $M_{\mathrm{I}}$, where $M_{\mathrm{P}}$ is the mass of particulate, in this case the $2 \mathrm{D}-\mathrm{MoSe}_{2}$ and $M_{\mathrm{I}}$ is the mass of the PLA used in the fabrication, i.e. $\%=\left(M_{\mathrm{P}} / M_{\mathrm{I}}\right) \times 100$. The maximum amount of 2D-MoSe ${ }_{2}$ that can be incorporated into the 2D$\mathrm{MoSe}_{2} / \mathrm{PLA}$ was found to correspond to $c a .10 \%$ as any further percentage incorporation increased the fluidity of the resultant polymer to such an extent where it was not possible to produce a filament via the method utilized herein. This is likely due to the weak interlayer forces between $2 \mathrm{D}-\mathrm{MoSe}_{2}$ sheets causing a lubricating effect. ${ }^{53}$ As a result of this a mass of $10 \% 2 \mathrm{D}-\mathrm{MoSe}_{2}$ to $90 \%$ PLA was pre-mixed utilizing a facile solution based mixing step, briefly the $2 \mathrm{D}-\mathrm{MoSe}_{2}$ was dispersed within xylene and heated (under reflux) at $160^{\circ} \mathrm{C}$ for 3 hours, the PLA was then added to the mixture and left for a further 3 hours (see Fig. 1(A)). The resulting homogenous (solution phase) mixture then was then recrystallized within methanol, and left to dry (at $50{ }^{\circ} \mathrm{C}$ in a fan oven) until the xylene had evaporated. The resulting $2 \mathrm{D}-\mathrm{MoSe}_{2}$ loaded PLA powder mix was then placed within a MiniCTW twin-screw extruder (ThermoScientific) at a temperature of $200{ }^{\circ} \mathrm{C}$ and a screw speed of $30 \mathrm{rpm}$, the diameter $(1.75 \mathrm{~mm})$ of the filament was controlled with a specific die with a set diameter (see Fig. 1(B)). The 3D printed designs were fabricated using a ZMorph ${ }^{\circledR}$ printer (Warsaw, Poland) with a direct drive extruder at a temperature of $200{ }^{\circ} \mathrm{C}$. The $3 \mathrm{D}$ printed designs were designed via the CAD software Solidworks, to create a circular disc electrode with a diameter of $3.5 \mathrm{~mm}$ and a thickness of $1.5 \mathrm{~mm}$, as seen in Fig. 1(C). The AME's were printed with a connecting strip allowing simple connection to a crocodile clip, as can be seen in Fig. 2(A). It is to be noted that the $10 \% 2 \mathrm{D}-\mathrm{MoSe}_{2} \mathrm{AME}$ 's were non-conductive, therefore the above fabrication technique was modified to include 5,10 and $15 \%$ mass incorporation of Super P. This was done to increase the number of electrical pathways within the AME and maximise conductivity, note the fabricated AMEs are denoted as $\mathrm{M}_{X \%} \mathrm{C}_{X \%}$ and $\mathrm{Pt} / \mathrm{C}_{X \%}$ where $\mathrm{M}$ represents $2 \mathrm{D}-\mathrm{MoSe}_{2}, \mathrm{C}$ is the electro-conductive carbon (Super $\mathrm{P}$ ), $\mathrm{Pt} / \mathrm{C}$ is the commercially sourced carbon with a $20 \%$ mass loading of $\mathrm{Pt}$ and $\mathrm{X} \%$ is the percentage incorporate within the PLA filament/AME. The $15 \%$ Super P was found to be the optimal mass of incorporation based on the compromise between increased percentage incorporation leading to increased conductivity but decreased printability.

\section{Author contributions}

Jack P. Hughes: performed experiments and acquired data. Pãmyla L. dos Santos: performed experiments and acquired the data. Michael P. Down: produced CAD designs. Christopher W. Foster: performed physicochemical characterisation of the materials. Juliano A. Bonacin: wrote the manuscript with coauthors. Edmund M. Keefe: produced CAD designs and input into AM. Samuel J. Rowley-Neale*: conceived the idea and designed the experiments. Produced bespoke filaments and additive manufactured electrodes. Wrote the paper with coauthors. Craig E. Banks*: conceived the idea, designed the experiments and wrote the paper with co-authors.

\section{Copyright}

The authors can confirm that all images and figures within the manuscript are original.

\section{Conflicts of interest}

The authors declare no competing interests. 


\section{Acknowledgements}

Funding from the Engineering and Physical Sciences Research Council (Reference: EP/P007767/1 and EP/N0011877/1), British Council Institutional Grant Link (No. 172726574) is acknowledged. The Manchester Fuel Cell Innovation Centre is funded by the European Regional Development Fund.

\section{References}

1 M. G. Schultz, T. Diehl, G. P. Brasseur and W. Zittel, Air Pollution and Climate-Forcing Impacts of a Global Hydrogen Economy, Science, 2003, 302, 624-627.

2 A. Ahmed, A. Q. Al-Amin, A. F. Ambrose and R. Saidur, Hydrogen Fuel and Transport System: A Sustainable and Environmental Future, Int. J. Hydrogen Energy, 2016, 41(3), 1369-1380.

3 P. Jiang, Q. Liu, Y. Liang, J. Tian, A. M. Asiri and X. Sun, A Cost-Effective 3D Hydrogen Evolution Cathode with High Catalytic Activity: FeP Nanowire Array as the Active Phase, Angew. Chem., 2014, 126(47), 13069-13073.

4 V. Pfeifer, T. E. Jones, S. Wrabetz, C. Massué, J. J. V. Vélez, R. Arrigo, et al. Reactive oxygen species in iridium-based OER catalysts, Chem. Sci., 2016, 7(11), 6791-6795.

5 S. J. Rowley-Neale, M. Ratova, L. T. N. Fugita, G. C. Smith, A. Gaffar, J. Kulczyk-Malecka, et al. Magnetron SputterCoated Nanoparticle MoS2 Supported on Nanocarbon: A Highly Efficient Electrocatalyst toward the Hydrogen Evolution Reaction, ACS Omega, 2018, 3(7), 7235-7242.

6 H. Wang, X. Wang, L. Wang, J. Wang, D. Jiang, D. Li, et al. Phase Transition Mechanism and Electrochemical Properties of Nanocrystalline MoSe2 as Anode Materials for the High Performance Lithium-Ion Battery, J. Phys. Chem. C, 2015, 119(19), 10197-10205.

7 S. Ji, Z. Yang, C. Zhang, Z. Liu, W. W. Tjiu, I. Y. Phang, et al. Exfoliated MoS2 Nanosheets as Efficient Catalysts for Electrochemical Hydrogen Evolution, Electrochim. Acta, 2013, 109, 269-275.

8 Z. Lei, S. $\mathrm{Xu}$ and P. Wu, Ultra-Thin and Porous MoSe2 Nanosheets: Facile Preparation and Enhanced Electrocatalytic Activity Towards the Hydrogen Evolution Reaction, Phys. Chem. Chem. Phys., 2016, 18(1), 70-74.

9 S. J. Rowley-Neale, D. A. C. Brownson, G. C. Smith, D. A. G. Sawtell, P. J. Kelly and C. E. Banks, 2D Nanosheet Molybdenum Disulphide (MoS2) Modified Electrodes Explored Towards the Hydrogen Evolution Reaction, Nanoscale, 2015, 7(43), 18152-18168.

10 X. Mao, J. Zou, D. Li, G. Zhao and Z. Song, MoSe2/graphite composite with excellent hydrogen evolution reaction performance fabricated by rapid selenization method, Appl. Surf. Sci., 2019, 471, 142-148.

11 C. Tsai, K. Chan, F. Abild-Pedersen and J. K. Norskov, Active edge sites in MoSe2 and WSe2 catalysts for the hydrogen evolution reaction: a density functional study, Phys. Chem. Chem. Phys., 2014, 16(26), 13156-13164.

12 S. Mao, Z. Wen, S. Ci, X. Guo, K. Ostrikov and J. Chen, Perpendicularly Oriented MoSe2/Graphene Nanosheets as
Advanced Electrocatalysts for Hydrogen Evolution, Small, 2015, 11(4), 414-419.

13 H. Tang, K. Dou, C.-C. Kaun, Q. Kuanga and S. Yang, MoSe2 nanosheets and their graphene hybrids: synthesis, characterization and hydrogen evolution reaction studies, J. Mater. Chem. A, 2014, 2, 360-364.

14 Q. Gong, L. Cheng, C. Liu, M. Zhang, Q. Feng, H. Ye, et al. Ultrathin MoS2(1-x)Se2x Alloy Nanoflakes For Electrocatalytic Hydrogen Evolution Reaction, ACS Catal., 2015, 5(4), 2213-2219.

15 X. Zhou, Y. Liu, H. Ju, B. Pan, J. Zhu, T. Ding, et al. Design and Epitaxial Growth of MoSe2-NiSe Vertical Heteronanostructures with Electronic Modulation for Enhanced Hydrogen Evolution Reaction, Chem. Mater., 2016, 28(6), 1838-1846.

16 S. J. Rowley-Neale, C. W. Foster, G. C. Smith, D. A. C. Brownson and C. E. Banks, Mass-producible 2DMoSe2 bulk modified screen-printed electrodes provide significant electrocatalytic performances towards the hydrogen evolution reaction, Sustainable Energy Fuels, 2017, 1(1), 74-83.

17 C. W. Foster, R. O. Kadara and C. E. Banks, Screen-Printing Electrochemical Architectures, Springer International Publishing, Germany, 2016.

18 M. Geissler and Y. Xia, Patterning: Principles and Some New Developments, Adv. Mater., 2004, 16(15), 1249-1269.

19 R. D. Farahani, M. Dubé and D. Therriault, ThreeDimensional Printing of Multifunctional Nanocomposites: Manufacturing Techniques and Applications, Adv. Mater., 2016, 28(28), 5794-5821.

20 K. Sun, T.-S. Wei, B. Y. Ahn, J. Y. Seo, S. J. Dillon and J. A. Lewis, 3D Printing of Interdigitated Li-Ion Microbattery Architectures, Adv. Mater., 2013, 25(33), 45394543.

21 G. Chisholm, P. J. Kitson, N. D. Kirkaldy, L. G. Bloor and L. Cronin, 3D printed flow plates for the electrolysis of water: an economic and adaptable approach to device manufacture, Energy Environ. Sci., 2014, 7(9), 3026-3032.

22 A. Ambrosi and M. Pumera, Self-Contained Polymer/Metal 3D Printed Electrochemical Platform for Tailored Water Splitting, Adv. Funct. Mater., 2018, 28(27), 1700655.

23 C. W. Foster, M. P. Down, Y. Zhang, X. Ji, S. J. Rowley-Neale, G. C. Smith, et al. 3D Printed Graphene Based Energy Storage Devices, Sci. Rep., 2017, 7, 42233.

24 C. Zheng, C. Chen, L. Chen and M. Wei, A CMK-5encapsulated MoSe2 composite for rechargeable lithiumion batteries with improved electrochemical performance, J. Mater. Chem. A, 2017, 5(37), 19632-19638.

25 S. Helveg, C. López-Cartes, J. Sehested, P. L. Hansen, B. S. Clausen, J. R. Rostrup-Nielsen, et al. Atomic-scale imaging of carbon nanofibre growth, Nature, 2004, 427(6973), 426-429.

26 P. S. M. Kumar, S. Thiripuranthagan, T. Imai, G. Kumar, A. Pugazhendhi, S. R. Vijayan, et al. Pt Nanoparticles Supported on Mesoporous CeO2 Nanostructures Obtained through Green Approach for Efficient Catalytic 
Performance toward Ethanol Electro-oxidation, ACS Sustainable Chem. Eng., 2017, 5(12), 11290-11299.

27 Z. Zhang, Y. Fu, X. Yang, Y. Qu and Z. Zhang, Hierarchical MoSe2 Nanosheets/Reduced Graphene Oxide Composites as Anodes for Lithium-Ion and Sodium-Ion Batteries with Enhanced Electrochemical Performance, ChemNanoMat, 2015, 1(6), 409-414.

28 T. Chen, Y. Liu, L. Pan, T. Lu, Y. Yao, Z. Sun, et al. Electrospun carbon nanofibers as anode materials for sodium ion batteries with excellent cycle performance, $J$. Mater. Chem. A, 2014, 2(12), 4117-4121.

29 B. Peng, Y. Xu, X. Wang, X. Shi and F. M. Mulder, The electrochemical performance of super $\mathrm{P}$ carbon black in reversible Li/Na ion uptake, Sci. China: Phys., Mech. Astron., 2017, 60(60), 064611.

30 M. Liu, Y. Niu, L. Yang, L. Yao, D. Lin, C. Shao, et al. Simultaneous formation of carbon nanosheet and loading of platinum nanoparticle to form platinum/carbon nanosheet composite and its electrocatalytic activity, Diamond Relat. Mater., 2018, 90, 79-83.

31 E. C.-D. Jesus, D. Santiago, G. Casillas, A. Mayoral, C. Magen, M. José-Yacaman, et al. Platinum Electrodeposition on Unsupported Single Wall Carbon Nanotubes and Its Application as Methane Sensing Material, J. Electrochem. Soc., 2012, 160(2), 98-104.

32 P. Sharma and R. Sharma, Platinum Functionalized Multiwall Carbon Nanotube Composites as Recyclable Catalyst for Highly Efficient Asymmetric Hydrogenation of Methyl Pyruvate, RSC Adv., 2015, 5(124), 102481-102487.

33 D. Nam, J.-U. Lee and H. Cheong, Excitation energy dependent Raman spectrum of MoSe2, Sci. Rep., 2015, 5, 17113.

34 M. Pawlyta, J.-N. Rouzaud and S. Duber, Raman microspectroscopy characterization of carbon blacks: Spectral analysis and structural information, Carbon, 2015, 84, 479-490.

35 S. V. Thoi, R. E. Usiskin and S. M. Haile, Platinum-decorated carbon nanotubes for hydrogen oxidation and proton reduction in solid acid electrochemical cells, Chem. Sci., 2015, 6(2), 1570-1577.

36 Y. Li, M. Zhang, X. Zhang, G. Xie, Z. Su and G. Wei, Nanoporous Carbon Nanofibers Decorated with Platinum Nanoparticles for Non-Enzymatic Electrochemical Sensing of H2O2, Nanomaterials, 2015, 5(4), 1891-1905.

37 K. Daniels, A. Obe, B. Daas, J. Weidner, C. Williams, T. Sudarshan, et al. Metal Catalyzed Electrochemical Synthesis of Hydrocarbons from Epitaxial Graphene, J. Electrochem. Soc., 2016, 163, 130-134.

38 I. N. Leontyev, D. V. Leontyeva, A. B. Kuriganova, Y. V. Popov, O. A. Maslova, N. A. Glebova, et al. Characterization of the electrocatalytic activity of carbon-supported platinum- based catalysts by thermal gravimetric analysis, Mendeleev Commun., 2015, 25(6), 468-469.

39 G. Paganoto, T. Evangelista, M. Guimarães and J. Ribeiro, Raman Spectroscopy and Electrochemical Investigations of Pt Electrocatalyst Supported on Carbon Prepared through Plasma Pyrolysis of Natural Gas, J. Spectrosc., 2015, 2015(329730), 1-7.

40 H. Wang, D. Kong, P. Johanes, J. J. Cha, G. Zheng, K. Yan, et al. MoSe2 and WSe2 Nanofilms with Vertically Aligned Molecular Layers on Curved and Rough Surfaces, Nano Lett., 2013, 13(7), 3426-3433.

41 L. Botta, R. Scaffaro, F. Sutera and M. C. Mistretta, Reprocessing of PLA/Graphene Nanoplatelets Nanocomposites, Polymers, 2018, 10(1), 18.

42 B. Hinnemann, P. G. Moses, J. Bonde, K. P. Jørgensen, J. H. Nielsen, S. Horch, et al. Biomimetic Hydrogen Evolution: MoS2 Nanoparticles as Catalyst for Hydrogen Evolution, J. Am. Chem. Soc., 2005, 127(15), 5308-5309.

43 Sigma-Aldrich, http://www.sigmaaldrich.com/catalog/ product/aldrich/204013 ?lang $=$ en\&region $=$ GB2019.

44 N. M. Marković, B. N. Grgur and P. N. Ross, TemperatureDependent Hydrogen Electrochemistry on Platinum LowIndex Single-Crystal Surfaces in Acid Solutions, J. Phys. Chem. B, 1997, 101(27), 5405-5413.

45 N. M. Marković and P. N. Ross Jr, Surface science studies of model fuel cell electrocatalysts, Surf. Sci. Rep., 2002, 45(4-6), 117-229.

46 A. B. Laursen, S. Kegnaes, S. Dahl and L. B. Chorkendorff, Molybdenum sulfides-efficient and viable materials for electro - and photoelectrocatalytic hydrogen evolution, Energy Environ. Sci., 2012, 5(2), 5577-5591.

47 A. F. Garcia-Miranda, C. W. Foster, P. J. Kelly, D. A. C. Brownson and C. E. Banks, Determination of the Electrochemical Area of Screen-Printed Electrochemical Sensing Platforms, Biosensors, 2018, 8(2), 52.

48 J. M. D. Rodríguez, J. A. H. Melián and J. P. Peña, Determination of the Real Surface Area of Pt Electrodes by Hydrogen Adsorption Using Cyclic Voltammetry, J. Chem. Educ., 2000, 77(9), 1195.

49 Sigma-Aldrich, http:/www.sigmaaldrich.com/catalog/ product/aldrich/209686? lang $=$ en\&region $=$ GB2019, updated 03/01/2019.

50 Sigma-Aldrich, http:/www.sigmaaldrich.com/catalog/ product/aldrich/778087?lang $=$ en\&region $=$ GB2018.

51 Sigma-Aldrich, http:/www.sigmaaldrich.com/catalog/ product/aldrich/738549? lang $=$ en\&region $=\mathrm{GB} 2019$.

52 Aesar A., http://www.alfa.com/en/catalog/H30253/2019.

53 T. Kubart, T. Polcar, L. Kopecký, R. Novák and D. Nováková, Temperature dependence of tribological properties of MoS2 and MoSe2 coatings, Surf. Coat. Technol., 2005, 193(1), 230233. 